\title{
The Factor of Main Characters' Consumer Behavior in Toy Story and Toy Story 2
}

\author{
Louis Adhitama \\ English Department, Faculty of Languages and Literature, Petra Christian University, Siwalankerto 121- \\ 131, Surabaya 60236, INDONESIA \\ E-mail: m11414020@john.petra.ac.id
}

\begin{abstract}
This thesis aims to know why the main characters of Toy Story and Toy Story 2 do excessive consumption on toys. Therefore, I will use the theory of consumer behavior to be applied on Andy, Sid, and Al as the consumers of toys. From this theory, I want to show that consumer behavior can be seen from internal and external traits. The internal trait means the consumer behavior is influenced by the inner side of consumers. On the other hand, the external trait means the consumer behavior is triggered by the outside factor of consumers' surroundings. I connected the analysis with consumer behavior theory by discussing the factors which have internal and external traits that cause the main characters to have consumer behavior. In the end, it can be concluded from Toy Story (1995), and Toy Story 2 (1999) that consumer behavior can influence children or adult for doing excessive consumption as the consumers of toys.
\end{abstract}

Keywords: Affective System, Cognitive System, Characteristic, Consumer Behavior, Consumption.

\section{INTRODUCTION}

Toy Story has two major characters with a strong consumptive behavior. They are Andy and Sid. These children are neighbors with different ways of consumptive behavior. Andy always gets toys as presents from his mother and his friends. He cherishes the toys so much and plays them with love. This shows positive consumptive behavior. On the other hand, Sid shows negative consumptive behavior by playing with his toys brutally. In other words, he tends to buy new toys and immediately wreck them by exploding them into ashes or switching some of the toys' parts with other toys. His consumptive behavior toward toys is done on purpose because it makes him happy.

Similar to Toy Story, the most prominent character in Toy Story 2 with his consumptive behavior is Al, the toy store owner called Al's Toys Barn. Al's consumptive behavior derives from his job as a toy seller. Besides selling toys, he also has a secret purpose of collecting rare toys, so that he could sell them to a toy museum in Japan. Al's consumptive behavior drives him crazy enough to steal another person's toy just because it is rare. Al's behavior shows that excessive consumption can drive a person to do bad things toward others. Like the famous proverb 'Homo Homini Lupus' according to the book entitle De Cive written by Thomas Hobbes, he defines that proverb as,

All men in the state of nature have a desire, and will to hurt, each but not proceeding from the same cause, neither equally to be condemn for one man according to that natural equality which is among us, permits as much to others, as he assumes to himself (which is an argument of a temperate man, and one that rightly values his power), supposing himself above others, will have a license to do what he lists and challenges respect, and honor, as due to him before others (Hobbes, 1642).

In other words, each person has a will to stand above others. It is a natural instinct for a person hurts other people for the sake of achieving his/her wishes and dream. For example, Al's consumptive behavior influences him to be a greedy individual who would do anything in order 
to get what he wants. Therefore, this quotation of Thomas Hobbes may give a picture that each consumer like Al has the desperate situation where he or she is pushed to take the other people's property in order to fulfill their satisfaction of doing consumption.

In order to analyze the factor that cause the owners in Toy Story and Toy Story 2 excessively consume toys, I will use Consumer Behavior Theory. This Theory is introduced by J. Paul Peter, a professor of Wisconsin University who taught variety of courses, one of the courses is consumer behavior. On the other hand, Jerry C. Olson as a professor in Pennsylvania State University helps professor Peter to introduce Consumer Behavior Theory. According to the book Consumer Behavior and Marketing Strategy written by J. Paul Peter and Jerry C. Olson, they define consumer behavior as "the dynamic interaction between affective response and cognitive response that human beings conduct the exchange aspect of their lives". In other words, consumer behavior involves the feelings and thoughts of people when they are doing or performing the consumption process (Peter and Olson, 2010, p.6). Consumer behavior is caused by two factors, in which the factors are affective system and cognitive system.

Affective response can cause people as consumers to have positive and negative emotion. Consumers' emotions are the main point whether they like the product or not. These emotions that come from consumers' affective response are produced by affective system. This system is the first factor that causes the main characters in Toy Story and Toy Story 2 to excessively consume toys. The affective system has five basic characteristics. According to Peter and Olson, "affective system's characteristics are largely reactive, little direct control, felt physically in the body, responding to any virtual type of stimulus, and learned since young age" (Peter and Olson, 2010, p.40-41). There are further explanations regarding these affective system's characteristics.

The first characteristic of affective system is largely reactive. It means the affective system triggers consumers to have spontaneous urge of doing consumption. In other words, consumers' affective system produces affective response immediately and automatically, if they see some trend products are sold in the market or seen in front of consumers' eyes. According to Peter and Olson, "an obvious example is color. Most consumers immediately have positive response when they see their favorite color on a trend product" (Peter and Olson, 2010, p.41). The second characteristic of affective system is little direct control. It means the consumers have less selfcontrol when they get a certain product as the result of buying and receiving from other people. Peter and Olson give an example "if a person is insulted by a rude clerk, his/her affective system may immediately or automatically produce feelings of frustration and anger" (p.41). The third characteristic of affective system is physical reaction on the body. It means that consumers' feelings can cause powerful physical reaction when they are doing consumption. Consumers' body movements often reflect to their affective state. The example of physical movements is smiling when happy, frowning when disturbed, and clenching fist when angry. In addition, through physical reaction of body movements, consumers can communicate their emotional states to other people. The fourth characteristic of affective system is responding to any virtual type of stimulus. This affective system's characteristic has an evaluative respond to a physical object, social situation, and consumers' own behavior. Peter and Olson show the example: "such as physical object \{I love my watch\}, social situation \{I disliked talking to the salesperson in the electronics store $\}$, and consumers' own behavior \{I am enjoy downloading tunes to my iPod\}" (p.41). The last characteristic of affective system is that the affective responses are learned since young age. Every consumer acquires affective response through early socialization experience as young children. Moreover, affective responses can be learned across different cultures, subculture, and other social groups.

On the other hand, the cognitive response refers to what consumers think and understand about products after they have them as their property that is produced by cognitive system. Knowledge and beliefs that consumers have developed through experiences in doing 
consumption and they (knowledge and beliefs) are stored in their memories. Cognitive system has two characteristics, in which they are product knowledge and integration process. Product Knowledge as the first characteristic of cognitive system concerns about various knowledge, meanings and beliefs in several products. Peter and Olson say that,

a consumer may have a knowledge about the characteristics of a famous brand of athletic shoes such as the air inserts in the heel, the outcomes of using the brand make me run faster, and the consumer is very satisfy with the shoes ability like he/she will be fit to wear the shoes (p.50).

Next, integration process as the second characteristic of cognitive system concerns how consumers combine knowledge from evaluation of products with affective response to choose and execute a behavior. They also said that "consumers combine knowledge and feelings as affective responses about a product to form an evaluation of the brand itself like these examples, I do not like Starbucks Coffee and Wrangler Jeans are better than Levi's" (p.49). Consumers combine knowledge and their affective responses with the purpose to choose a decision in doing consumption.

\section{THE MAIN CHARACTERS' CONSUMER BEHAVIOR ON TOYS}

Consumer behavior that happens in Toy Story and Toy Story 2 is caused by two factors, which are affective response and cognition response. These responses make the main characters in Toy Story and Toy Story 2 have consumer behavior with toys. There are three main characters that have compulsive behavior in Toy Story and Toy Story 2. The main characters are Andy, Sid, and Al. In addition, their excessive consumption happens because of two systems that produce affective response and cognition response. These systems are affective system and cognitive system.

\section{The Affective System of Andy, Sid, and Al}

In this section, the discussion about affective system will be applied toward the main characters in Toy Story and Toy Story 2 because affective system is the first cause why the main characters do excessive consumption. There are five characteristics of affective system that will be applied to Andy, Sid, and Al. These characteristics of affective system will prove that the main characters have consumer behavior to do consumption on toys in according to their feelings through different aspects.

\section{Andy's Excitement Response}

In this sub-heading, one of the main factors that causes Andy to have consumer behavior is affective system that produces affective response. There are two characteristics of affective responses that make Andy have consumer behavior. One of those characteristics is largely reactive. This characteristic gives a large impact to children environment of consuming Buzz Lightyear, including Andy. Because Buzz Lightyear's popularity gives impact to Andy, he has spontaneous urge to consume Buzz Lightyear after he receives it from his mother as the birthday present. Andy's excitement response as feeling happens when he plays with Buzz Lightyear. This the result of his production of affective system. The excitement response becomes the proof that Andy has consumer behavior. This is where largely reactive as the part of affective system's characteristics comes in. Because of Buzz Lightyear's popularity, it triggers Andy's excitement response to do consumption with his space ranger toy without stopping. Andy's excitement response of non-stop doing consumption is caused by affective system. Andy's excitement response also influences his friends to have the same consumer behavior like him. 
In addition, another characteristic of affective response that makes Andy have consumer behavior is little direct control. The affective system works well immediately to produce affective response or feelings on Andy, such as excitement. In other words, Andy's excitement response causes him to lose self-control in doing consumption, and this excitement influences his consumer behavior to do excessive consumption on a toy like Buzz Lightyear. The example below shows that Andy has less self-control over his behavior of having excitement feeling during his playtime. The excitement response of playing toys as consumption is the part of Andy's affective response. One clear example that shows Andy's imagination make him lose control in consuming toys is crashing Buzz Lightyear toward Hamm, the piggy bank. In addition, imagination is the source of Andy who has less-control in playtime because imagination gives him positive response such as excitement feeling for doing consumption on Buzz Lightyear. Therefore, through this imagination, Andy cannot control his excitement response in consuming Buzz Lightyear, and it influences his consumer behavior for playing without stopping.

\section{Sid's Physical Reaction of Affective Response}

In this part, one of the affective system's characteristics that causes Sid to have consumer behavior is physical reaction on the body. In contrast with Andy as a nice and good child who has positive affective response when he does consumption on toys, Sid as Andy's neighbor has an uncontrol temper and impolite behavior along with his negative response to do consumption on toys. Sid's anger is seen from his facial expression as he raises his eyebrows, sharpens his gazes toward the arcade crane game, opens his mouth, and then clenches his fist to punch the arcade crane's glass. Sid pours out his anger toward the arcade crane game because he fails to get the toys as prizes. Through the anger reaction that caused by his uncontrol temper, it shows that Sid has a bigger consumer behavior with strong determination in collecting toys and adding them as his collection, and if Sid fails to collect them, this failure can cause him to let out his anger expression.

There is another example of Sid's affective system that produces negative response when he is doing consumption on toys. Sid's expression is annoyed because he feels really upset when the game's duration is out. Moreover, this facial expression triggers his body movements to step on the arcade game with holding the little bat with both hands as if he wants to break the arcade game machine. Through his body movements, it proves that Sid is not satisfied to play the arcade game due to his bigger consumer behavior in consuming the game as a toy, and what Sid needs to fulfill his bigger consumer behavior is playing the arcade game in long duration instead of short time.

\section{Andy and Al's Evaluative Response}

Andy as the owner of Woody and Buzz Lightyear has evaluative response at his precious toys as physical objects. This evaluative response appears when Andy distinguishes toys that he often consumes and rarely consumed. Thus, Andy's evaluative response influences his consumer behavior in doing excessive consumption to Woody and Buzz Lightyear, and the example that related to this statement can be seen from Andy's merchandise collection. Moreover, one of the common toy merchandises are posters which have theme related on the type of those toys. Then, these posters of Woody and Buzz Lightyear refer to Andy's evaluative response that he always consumes toys which have human physical features. Through his physical object evaluative response, it is seen that Andy always consumes toys that have human's physical features because their body parts such as hand and legs can be moved freely. These toys also have voice feature as if they are really talking like a real person, in which these physical features attract Andy's attention for playing more with these toys type. On the other 
hand, Andy rarely consumes other toys except Woody and Buzz Lightyear because of his evaluative response on them as the toys which do not have human physical features. Moreover, the parts of toys' body such as hands and legs cannot moved freely, and these toys also do not have any voice feature like a real person. Thus, Andy rarely consumes toys which do not have human physical features because according to him, those toys do not attract too much attention for Andy to excessively consume them. Therefore, the difference between toys that Andy often consumes and rarely consumes indicates that he is very attracted with the toys which have human appearance. In addition, this difference influences Andy to make a priority in consuming Woody and Buzz Lightyear according to his evaluative response of physical object.

The next main character from Toy Story 2 who has consumer behavior that related to the characteristic of evaluative response is $\mathrm{Al}$, the owner of a toy store named Al's Toy Barn. $\mathrm{Al}$ has evaluative response in social situation and his own consumer behavior. As a toy store owner, Al has been collecting many variations of toys as the stock as his products by displaying them on shelfs at the store. By displaying stock of toys at the store, Al's activity in collecting toys is considered as consumer behavior. In addition, the quiet atmosphere indicates a big toy store does not have a single customer which results in the absence of social situation. This social situation of having less-customers becomes an evaluative response for $\mathrm{Al}$ to respond on this problem. Otherwise, his consumer behavior in collecting toys as stocks and displaying them to get money will be a waste effort for him. Through evaluative response toward his social situation, $\mathrm{Al}$ immediately responds to this problem by promoting his toy store with the products. This promotion is the only solution for $\mathrm{Al}$ as the result of his evaluative response to solve the problem of having less-customers. Al's immediate response to solve his business problem is seen from how he makes an advertisement as the promotion of his toy store, Al's Toy barn along with his toy products. This promotion indicates an evaluative response to Al's own behavior for working hard in attracting the attention of customers. In addition, the evidence of Al's hard work to attract the attention of customers through television advertisement is supported by his policy of giving one-dollar price for all type of toys in his toy store, and he also wears a property such as chicken costume that becomes the symbol of Al's toy Barn. Furthermore, if Al's hard work to attract customers' attention is successful as the result of his evaluative response, he will get a lot of money from his stock of toy sales, and Al will use that money to collect the other toys again as the new stocks in his toy store. In that way, Al will never stop in collecting toys as the form of his consumer behavior.

\section{Supportive Response as Andy's Lesson}

In this sub-heading, the last characteristic of affective system that causes Andy to have consumer behavior is learning affective response since young age. According to this characteristic, affective response is learned through different culture, subcultures, and social groups. The characteristic on this sub-chapter will focus in social group, which is the family. Next, Andy's mother named Mrs. Davis as the member of the family places an important role in supporting Andy's consumer behavior. Mrs. Davis needs to give supportive response to Andy due to his problem in consumption. These consumption problems that are experienced by Andy cause him to lose his consumer behavior in doing consumption. However, from his experience of having consumption problems along with supportive response given by Mrs. Davis, Andy can learn that positive response is needed as the resolution to deal with each problem. If Andy can learn that positive response from his mother's supportive response, he can regain his consumer behavior.

The consumption problem that is experienced by Andy is when he loses both Woody and Buzz Lightyear as his favorite toys. This problem causes Andy's affective system to produce negative response such as fear response. Moreover, this conversation has a meaning that Mrs. Davis knows if Andy needs toys to fill his days with playing because toys are what all children 
consume as their consumption. The evidence that shows Andy's fear response can be seen from a quotation above as Andy says, "but what if we leave them behind?" and this quotation also proves if Andy has been spending much time to consume on Woody and Buzz Lightyear by playing with them every day. Next, the fear response can influence Andy to lose his will in doing consumption if he always keeps his consumer behavior on the negative response in this consumption problem. Therefore, this is the right situation for Mrs. Davis's role to give response like supporting Andy to let go his fear response, in which this negative response is an obstacle for him to regain the consumer behavior. The proof when Mrs. Davis supports her son is seen from a quotation as she says "oh, don't worry, honey, I'm sure we'll find Woody and Buzz before we leave tomorrow". In addition, through this quotation Mrs. Davis shows that she is supporting Andy's consumer behavior in doing consumption on his favorite toys by comforting Andy's fear response, and she helps him in searching for Woody and Buzz Lightyear. Having consumption problem gives Andy a lesson that negative response such as sadness will not help him to regain his consumer behavior, but a positive response like not giving up is the best solution of this problem. A quotation below shows that Andy regains his consumer behavior after he learns that positive response is the best solution for his consumption problem. Andy's positive response appears as he finds his favorite toys inside the car. This discovery moment is the table turn for Andy's fear response, when his fear response suddenly changes into happiness response. Because of this sudden change in affective response, Andy regains his consumer behavior in consuming toys, especially to both Woody and Buzz Lightyear as his favorite toys. Both toys are the main reason why Andy has bigger consumer behavior to play with them in order to reach his own satisfaction. The proof which shows that Andy regains his consumer behavior is quoted from the phrase "(picking up the toys) Woody! Buzz!" This situation happens because Andy finally learns if the positive response that he gets through his mother's supportive response can be a solution for him to solve the consumption problem of losing Woody and Buzz Lightyear. Furthermore, his consumption problem is not only about losing both his favorite toys, but also breaking a part of Woody due to his carelessness act.

\section{The Cognitive System of Andy, Sid, and Al in Decision Making}

In this section, the discussion about cognitive system will be applied toward the main character in Toy Story and Toy Story 2 because cognitive system is the second cause why the main characters have consumer behavior. There are two characteristics of cognitive system that give influence for the main characters to do excessive consumption. Moreover, these characteristics of cognitive system will prove that knowledge and integration process as two characteristics of cognitive system will be applied to Andy, Sid, and $\mathrm{Al}$ in making decision according to their judgement why they choose that toys as their main consumption.

\section{Al's Knowledge about Toys}

In this sub-heading, one of the main factors that causes $\mathrm{Al}$ to have consumer behavior is product knowledge. Knowledge is the first characteristic of cognitive system that becomes a judgment for consumers to make a decision about what they are going to do with the product. Moreover, due to Al's job as the toy store owner, he has a wide knowledge about toys' characteristics by collecting many toys that have good quality and high value for selling to consumers, especially children. In the Toy Story 2 movie, Al uses knowledge as the part of his cognitive response to collect Woody, the core member of Woody's Roundup collection for making him rich instantly. $\mathrm{Al}$ chooses to get rich faster by collecting rare toys because of the certain circumstance, in which his toy store has not been visited by customers for a long time. Therefore, by collecting the rare toys, Al's consumer behavior is considered as excessive consumption. In the cognitive response, there is a knowledge about parts of the certain toy that stored in Al's memory, in which it helps him to describe Woody as the rare toy for completing his Woody's Roundup 
collection. The knowledge that is stored in Al's memory comes from his experience in collecting toys in order to fill stock at his toy store. Having knowledge in variety of toys becomes Al's specialty. In addition, the outcome of Al collecting Woody's Roundup collection is selling them to foreign collector in order to get a lot of money. By selling Woody's Roundup collection to foreign collector, $\mathrm{Al}$ is satisfied by getting money. He uses that money to collect more toys as new stock in his toy store as a proof that he is having consumer behavior.

The second example that shows Al's cognitive system produces cognitive response (knowledge) is seen from how Al uses his knowledge to treat rare toy like Woody with the right judgment. Each product has durability that decreases as the time flies. Sheriff Woody as the toy product also has its own durability, where it can decrease as the time goes by. In this urgent situation, Al's cognitive system produces a cognitive response such as anxiety response toward Woody's condition. According to Oxford Dictionary, anxiety is "a feeling of worry, nervousness, or unease about something with an uncertain outcome" (oxforddictionaries.com). The anxiety response shows that $\mathrm{Al}$ has the fear of failing to carry out the plan to sell the Woody's Roundup. If $\mathrm{Al}$ fails to carry out the plan, he cannot get income to collect and display more toys as his consumer behavior. Moreover, Al has two choices whether he fixes Woody's arm on his own or asks someone who has an experience in fixing broken toys. In the last minute, before it is sold to the foreign collector, $\mathrm{Al}$ makes a good decision to call the toy specialist that has the experience in fixing broken toys because he believes in his own knowledge to repair Woody's broken arm by calling the right person. In addition, the satisfaction of getting money and the anxiety in an urgent situation are responses that are related to Al's decision making in choosing the famous toys collection for sale and calling toy specialist to repair Woody's broken arm. Getting a lot of money from sales of Woody's Roundup by using his knowledge, $\mathrm{Al}$ can use that money to collect more toys and display them. Therefore, doing consumption for the sake of money can cause Al's consumer behavior to grow bigger.

\section{Andy and Sid's Integration Process}

In this sub-heading, one of the main factors that causes Andy and Sid to have consumer behavior is integration process. Integration process as the part of cognitive response is the second characteristic of cognitive system that becomes a judgment for consumers to make a decision about which product to be used in consumption. This judgment is combined between consumers' knowledge with their feelings as affective response. Moreover, this characteristic influences Andy to make a decision to choose Buzz Lightyear as a suitable toy to be played more often than Sheriff Woody. Andy chooses Buzz based on integration process, where he combines the common knowledge about Buzz Lightyear as famous toy with his feeling of happiness in doing consumption. The popularity of Buzz Lightyear gives impact around children's environment, including Andy. In addition, Buzz Lightyear's popularity tells a knowledge about its various features to Andy through television advertisement, and this knowledge indirectly influences Andy to choose a decision in doing consumption on Buzz Lightyear as the part of integration process. Therefore, this knowledge of Buzz Lightyear as the part of integration process gives an impact on Andy's consumer behavior to always play with the space ranger toy after he makes a choice to non-stop consuming it. Besides knowledge of Buzz Lightyear as a sub-factor to complete his integration process, it is also combined with Andy's feeling of happiness as affective response when he is playing with Buzz. This happiness happens because he got the space ranger toy that is famous on the market and his environment as his collection. Andy's happiness response influences him to make a home-made costume similar to Buzz Lightyear based on his knowledge. Making a costume for doing cosplay is considered as Andy's way to show his consumer behavior due to the effect of Buzz Lightyear's popularity. Therefore, Buzz Lightyear's popularity causes Andy to choose it as his 
main consumption through the integration process as a judgment, where he uses knowledge and his happiness feeling as affective response to consume more on Buzz Lightyear than Woody.

Next, the main character from Toy Story who has judgment in making decision about which product is used in consumption is Sid. As I state before, judgment is the part of integration process where consumers choose their product based on knowledge and affective response in order to do the consumption. Moreover, Sid chooses Buzz Lightyear as his priority after he got Woody and Buzz Lightyear from arcade game and plans to explode Buzz with the explosive as the act of doing consumption. The reason Sid wants to explode Buzz Lightyear and not Woody is because both Buzz Lightyear and the explosive rocket have a similar theme about outer space. Moreover, his knowledge about outer space theme makes him interested to play with Buzz and the rocket by making them explode together. The quotation below shows that Sid uses his knowledge in choosing Buzz Lightyear as the main consumption. Knowledge is not the only sub-factor that helps Sid to complete his integration process, but it also combines with Sid's excitement feeling as affective response when he wants to explode Buzz Lightyear, the space ranger toy in astronaut style. This excitement feeling appears as he got the best match of material consumption between astronaut and explosive rocket, in which they are related to the outer space theme based on Sid's knowledge. Therefore, the similar outer space theme as a knowledge causes Sid to choose Buzz Lightyear as his main consumption through the integration process as the form of consumer behavior, in which he also combines this knowledge with his feeling in order to complete the integration process.

\section{CONCLUSION}

In conclusion, the analysis of Toy Story and Toy Story 2 has proven that both affective system and cognitive system cause the main characters' consumer behavior to have an urge in doing excessive consumption on toys. The production of affective response by affective system proves that the main characters consume toys with their feelings through different aspects.

Furthermore, I found if the main characters either children such as Andy and Sid or adult like Al have the same feeling of happiness for doing consumption on toys as seen from the five aspects of affective system. In addition, the cognitive system also proves that the main character makes a decision to choose one toy from collection through the judgement based on the main characters' own knowledge and integration process. Therefore, by choosing the decision of consuming the best toy in according to both aspects that are influenced by the internal and the external traits, these main characters like Andy, Sid, and Al are surely doing excessive consumption without stopping.

\section{REFERENCES}

Daemon, Ioreks. (2015). All Pixar short films. Retrieved April 20, 2015, from https://www.imdb.com/list/ls076836092/

Hobbes, Thomas. (1642). De cive. (Howard Warrander. Ed.). New York: Oxford University Press.

Toy Story synopsis. (1995). Retrieved November 19, 1995, from https://www.imdb.com/title/tt0114709/plotsummary?ref_=tt_stry_pl\#synopsis

Toy Story 2 synopsis. (1999). Retrieved November 13, 1999, from https://www.imdb.com/title/tt0120363/plotsummary?ref_=ttpl_sa_2\#synopsis

Kehr, David. (1998). Animation motion picture. Retrieved July 20, 1998, from https://www.britannica.com/art/animation

Lasseter, John. (1995). Toy Story final draft. Retrieved November 19, 1995, from https://www.imsdb.com/scripts/Toy-Story.html

Lasseter, John. (1999). Toy Story 2 script. Retrieved November 13, 1999, from https://www.scripts.com/script.php?id=toy_story_2_22158 
Lawson, Kat. (2015). A brief history of Pixar Animation Studios. Retrieved February 11, 2015, from https://www.thefilmagazine.com/a-brief-history-of-pixar-animation-studios/

Lexico powered by Oxford. (2019). Anxiety. Retrieved July 6, 2019, from https://www.lexico.com/en/definition/anxiety

Peter, J. Paul \& Olson, Jerry. C. (2010). Consumer behavior and marketing strategy (9th ed). New York: The McGraw Hill-Companies, Inc.

Toy Story. Dir. John Lasseter. Perf. Tom Hanks, Tim Allen, John Morris, Erik Von Detten, and Laurie Metcalf. Walt Disney and Pixar Animation, 1995. DVD.

Toy Story 2. Dir. John Lasseter. Perf. Tom Hanks, Tim Allen, Wayne Knight, John Morris, and Laurie Metcalf. Walt Disney and Pixar Animation, 1999. DVD.

Weller, Chris. (2015). The uniquely powerful reason why pixar movies are so good. Retrieved July 30, 2015, from https://www.businessinsider.com/why-pixar-movies-are-so-good2015-7/?IR=T 